\title{
Interleukin 1 Induces Cultured Human Endothelial Cell Production of Granulocyte-Macrophage Colony-stimulating Factor
}

\author{
Colin A. Sieff, Schickwann Tsai, and Douglas V. Faller \\ Division of Pediatric Oncology, The Children's Hospital and Dana-Farber Cancer Institute, \\ and Department of Pediatrics, Harvard Medical School, Boston, Massachusetts 02115
}

\begin{abstract}
Monokine-stimulated endothelial cells are known to produce both burst- and colony-stimulating activities, but neither the nature of the monokine nor the hematopoietic growth factor(s) produced is known. We show by mRNA analysis that an immortalized line of human endothelial cells constitutively produce granulocyte-macrophage colony-stimulating factor. Furthermore, interleukin 1 and tumor necrosis factor induce early passage human umbilical endothelial cells to produce the same growth factor.
\end{abstract}

\section{Introduction}

Pluripotent stem cells and progenitors proliferate and differentiate only in the microenvironment of bone marrow, liver, or spleen, but the precise roles of the reticular, macrophage, and endothelial cells comprising this hematopoietic microenvironment are uncertain $(1,2)$. We recently demonstrated that a stromal reticular fibroblastoid cell strain produces a factor (or factors) with colony-stimulating activity (CSA) ${ }^{1}$ and burst-promoting activity (BPA), capable of inducing the formation of granulocyte-macrophage colony-forming units (CFU GM), erythroid burst-forming units (BFU E), and mixed granulocyte erythroid macrophage CFU (3). Cultured human endothelial cells have also been shown to produce CSA $(4,5)$ and BPA (6), whereas monocytes and/or macrophages not only produce CSA $(7,8)$, BPA $(9,10)$, and/or factors that inhibit colony formation (11), but also secrete a monokine, "monocyte-derived recruiting activity," that increases CSA and BPA production by endothelial cells $(12,13)$, fibroblasts (14), and T lymphocytes (15). Neither the monokine nor the specific CSA/BPA produced have been identified.

In this paper we show that an immortalized line of human endothelial cells constitutively produces granulocyte-macrophage colony-stimulating factor (GM CSF), a multilineage he-

Address correspondence to Dr. Sieff, Room 1630, Dana-Farber Cancer Institute, 44 Binney Street, Boston, MA 02115.

Received for publication 23 May 1986.

1. Abbreviations used in this paper: BFU E, erythroid burst-forming unit; BPA, burst-promoting activity; CFU E, erythroid colony-forming unit; CFU GM, granulocyte-macrophage colony-forming unit; CM, conditioned medium; CSA, colony-stimulating activity; GM CSF, GM colony-stimulating factor; HEC KSV, human endothelial cells immortalized by the Kirsten sarcoma virus; HUVE, human umbilical vein endothelial cells; IL-1, interleukin 1, IFN, interferon; Mo-CM, Mo T lymphoblast cell line CM; TNF, tumor necrosis factor.

J. Clin. Invest.

(c) The American Society for Clinical Investigation, Inc.

0021-9738/87/01/0048/04 \$1.00

Volume 79, January 1987, 48-51 matopoietin (16). We also demonstrate that both the monokines interleukin 1 (IL-1) and tumor necrosis factor (TNF) induce early passage human umbilical vein endothelial cells (HUVE) to produce GM CSF.

\section{Methods}

Bone marrow samples. Normal human bone marrow was obtained by aspiration from adult volunteers. Approximately 5-15 $\mathrm{ml}$ from one to two aspirations was collected into sterile syringes containing preservativefree heparin.

Cell separation procedures. The marrow suspensions were separated over Ficoll-Paque $(1.007 \mathrm{~g} / \mathrm{ml})$ (Pharmacia Fine Chemicals, Piscataway, $\mathrm{NJ}$ ) at $400 \mathrm{~g}$ for $40 \mathrm{~min}$ at $20^{\circ} \mathrm{C}$ and the interface mononuclear cells collected, washed three times, and resuspended in Iscove's modified Dulbecco's medium containing $20 \%$ fetal calf serum (FCS). The cells were incubated in 100-mm tissue culture dishes (Lux, Miles Laboratories Inc., Naperville, IL) overnight at $37^{\circ} \mathrm{C}$ and the nonadherent cells removed with two gentle washes and centrifuged. The progenitors in the nonadherent cell fraction were enriched by immunoadsorption to Ig-coated plates (panning), as previously described (17). Briefly, bone marrow cells were incubated at $4^{\circ} \mathrm{C}$ for $30 \mathrm{~min}$ with optimal concentrations of a panel of eight monoclonal antibodies directed against myeloid (Mol [18], My8 [19], TG1 [20], and Leu M1 [Becton-Dickinson \& Co., Paramus, NJ] [7] erythroid [glycophorin A-10F7] [21], and lymphoid [Leu 1, 5, and 12] [Becton-Dickinson \& Co.]) maturation antigens. The cells were washed twice in Iscove's modified Dulbecco's medium containing $2 \%$ FCS and once in phosphate-buffered saline (PBS) $/ 5 \%$ FCS, resuspended at 5-6 $\times 10^{6} / \mathrm{ml}$ in PBS $/ 5 \% \mathrm{FCS}$, and 4-5-ml aliquots incubated at $4^{\circ} \mathrm{C}$ for $1 \mathrm{~h}$ on 100 -mm plastic bacteriological petri dishes (Fisher Scientific Co., Pittsburgh, PA) that had been previously coated with rabbit antimouse Ig. Antibody-negative cells $\left(\mathrm{Ab}^{-}\right)$were removed and washed twice by gently swirling, tilting, and decanting. A second incubation on another antibody-coated plate was carried out to ensure removal of all antibodylabeled cells.

Preparation of Ig-coated plates. Panning was carried out by minor modifications of the method of Wysocki and Sato (22). $100 \times 15-\mathrm{mm}$ Polystyrene bacteriological petri dishes (No. 8-751-12; Fisher Scientific Co.) were incubated at room temperature with $10 \mathrm{ml}$ of affinity-purified rabbit anti-mouse IgG + IgA + IgM heavy and light chain Ig (Zymed Laboratories, Inc., San Francisco, CA) diluted to $10 \mu \mathrm{g} / \mathrm{ml}$ in PBS. After $40 \mathrm{~min}$, the plates were washed three times in PBS and then incubated at $4^{\circ} \mathrm{C}$ in $5 \mathrm{ml} \mathrm{PBS} / 1 \%$ FCS until required.

Culture procedures. The bone marrow cells were cultured in a mixture containing 30\% FCS, $1 \%$ bovine serum albumin (BSA; Sigma Chemical Co., St. Louis, MO), $10^{-4} \mathrm{M}$ mercaptoethanol (Sigma Chemical Co.), penicillin/streptomycin, and $0.9 \%$ methyl cellulose. Varying concentrations of the conditioned media to be tested or Mo-cell lymphoblast lineconditioned medium (Mo-CM) as a positive control (provided by Drs. D. Golde and J. Gasson, University of California at Los Angeles, School of Medicine, Los Angeles, CA) were added on day 0, and on day 3 human urinary erythropoietin (Terry Fox Laboratories, Vancouver, B. C., Canada) at $2 \mathrm{U} / \mathrm{ml}$ was added to the cultures. The final cell concentration was $5 \times 10^{3} / \mathrm{ml}$ and $0.5-\mathrm{ml}$ duplicates were plated in flat-bottomed 24-well tissue culture plates (Linbro; Flow Laboratories, Inc., McLean, VA) and incubated at $37^{\circ} \mathrm{C}$ in a high humidity $5 \% \mathrm{CO}_{2} / 95 \%$ air incubator. BFU E and CFU GM were counted on day 14. 
Cell lines. HUVE cells were grown in culture as previously described (Faller, D. V., D. Ginsburg, T. Collins, J. Pober, and R. Tantravahi, manuscript submitted for publication) on gelatin-coated plates in the presence of heparin and endothelial cell growth factor supplement (Sigma Chemical Co.) in M199 medium (Gibco, Grand Island, NY) with $20 \%$ FCS. Cells at passage 4-10 were used in these studies. HUVE at confluence in six-well tissue culture plates $\left(9.6 \mathrm{~cm}^{2}\right.$, Nunc, USA/Scientific Plastics, Ocala, FL) were incubated in $4 \mathrm{ml}$ of HUVE growth medium/well-containing purified human IL-1 (p 17; Genzyme Corp., Boston, MA), recombinant human IL-1 beta (p 17; Genzyme Corp.), recombinant human IL-2 (Biogen, Cambridge, MA), recombinant human interferon gamma ( $\gamma$ IFN; Genentech Inc., San Francisco, CA), or recombinant human TNF (Genentech Inc.) at the concentrations described in the text. Medium was harvested after $48 \mathrm{~h}$, filtered, and stored at $-20^{\circ} \mathrm{C}$. The human endothelial cell line immortalized by the Kirsten sarcoma virus (HEC KSV) (Faller, D. V., et al., and reference 23), and immortalized human synovial cells (23) were also plated in six-well tissue culture plates at the same density as HUVE, and the medium was harvested after $48 \mathrm{~h}$ for BPA/CSA and GM CSF assay. Cell line HEC KSV was grown in the same M199 medium as the HUVE. The synovial cells were grown in Dulbecco's modified Eagle's medium with 10\% FCS (Gibco).

Cytoplasmic RNA analysis for GM CSF. RNA was extracted from $10^{6} \mathrm{HEC} \mathrm{KSV}$, primary human foreskin fibroblasts, or HUVE (with or without a 48-h exposure to recombinant human IL-1 at a concentration of $10 \mathrm{U} / \mathrm{ml}$ ) as previously described (24). Serial dilutions of the RNA preparations were spotted onto nitrocellulose filters and hybridized to a ${ }^{32}$ P-labeled cDNA probe complementary to human GM CSF (25). Labeling of the probe, hybridization conditions, and wash conditions were as described. Autoradiography was carried out at $-70^{\circ} \mathrm{C}$ using enhancing screens (Dupont Co., Wilmington, DE). The intensity of the spots was determined by a densitometric scanner (Helena Laboratories, Beaumont, TX).

\section{Results}

We previously reported that enriched bone marrow progenitor cells, depleted of known accessory "helper" cell populations, were totally dependent on exogenous BPAs and CSAs for BFU $E$ and CFU GM proliferation in vitro (17). In the series of experiments reported below, $0.5-3.1 \%$ of the final enriched cell fraction formed BFU E and 1.0-2.3\% formed CFU GM-derived colonies, with progenitor recovery ranging from 19 to $94 \%$.

Immortalized human endothelial cells produce BSA and CSA. Conditioned medium (CM) from an HEC KSV was tested on enriched bone marrow progenitors in a sensitive BPA/CSA assay. Fig. 1 shows that the medium contained BPA and CSA (Fig. 1,

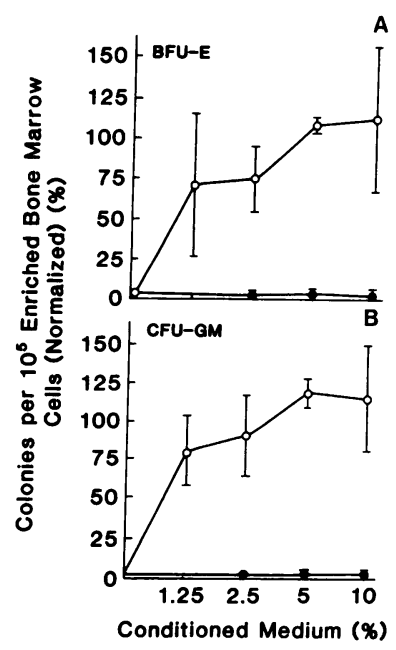

Figure 1. Response of enriched bone marrow BFU $\mathrm{E}(A)$ and $\mathrm{CFU}$ $\mathrm{GM}(B)$ to increasing concentrations of medium conditioned by immortalized human endothelial cells (open circles). To pool results from a series of experiments, the data from three experiments are normalized with the colony number induced by $5 \%$ Mo-CM taken as $100 \%$. CM from immortalized human synovial cells ( filled circles) fail to induce colony growth (two experiments). Error bars, 1 SD.
$A$ and $B$, respectively). Data from three experiments are normalized with the colony number induced by $5 \%$ Mo-CM taken as $100 \%$. The HEC KSV-conditioned medium was at least as active as Mo-CM, which induced 620-1260 BFU E and 16602200 CFU GM-derived colonies. In two experiments, CM from human synovial cells immortalized by the same virus (HSC KSV) were negative in the assay for both BPA and CSA, as was growth factor medium alone. It was possible that synovial cell $\mathrm{CM}$ contained an inhibitor that masked a stimulatory effect. Our observation that IL-1 induces both HSC KSV and fibroblasts from other sources to release BPA/CSA makes this very unlikely (manuscript in preparation) and therefore we did not carry out further mixing studies to exclude the presence of an inhibitor.

IL-1 and TNF markedly enhance BPA/CSA production by primary human endothelial cells. CM derived from HUVE cultured in medium alone showed low but detectable levels of BPA and CSA (Fig. 2, $A$ and $B$, respectively). CM (5\%) from HUVE incubated in purified human IL-1 $(10 \mathrm{U} / \mathrm{ml})$ or recombinant TNF $(1,000 \mathrm{U} / \mathrm{ml})$ markedly increased both BFU E- and CFU GM-derived colony number, in contrast to CM from HUVE incubated with the lymphokines IL-2 or $\gamma$ IFN, which had no effect on CSA/BPA production. When enriched bone marrow progenitors were incubated in endothelial growth medium alone or medium supplemented with IL-1, TNF, IL-2, or $\gamma$ IFN, no CSA/BPA was observed. To investigate the IL-1/TNF effect more fully, enriched bone marrow progenitors from three different aspirates were cultured with different concentrations of medium conditioned by unstimulated HUVE or HUVE incubated in either purified human IL-1 $(10 \mathrm{U} / \mathrm{ml})$ or recombinant TNF $(1,000 \mathrm{U} / \mathrm{ml})$. It is evident from Fig. 3 that BFU E and CFU GM showed a detectable response to unstimulated HUVE CM. BFU E (Fig. $3 \mathrm{~A}$ ) showed a marked response to CM from both IL-1 - and TNF-treated HUVE, which did not plateau at $10 \%$

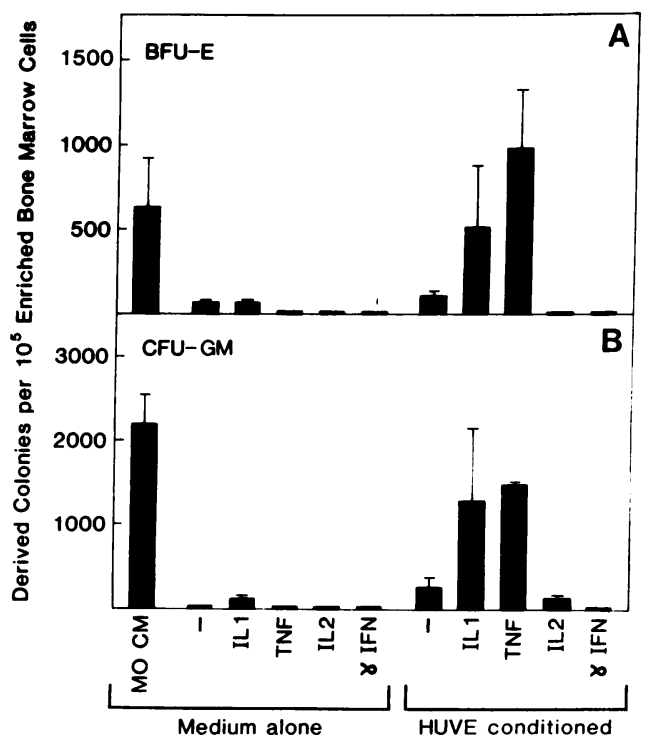

Figure 2. Response of enriched bone marrow BFU E $(A)$ and CFU $\mathrm{GM}(B)$ to $5 \% \mathrm{vol} / \mathrm{vol} \mathrm{Mo}-\mathrm{CM} ; 5 \%$ endothelial growth medium alone $(-)$ or supplemented with purified human IL-1 $(10 \mathrm{U} / \mathrm{ml})$, recombinant TNF $(1,000 \mathrm{U} / \mathrm{ml})$, IL-2 $(50 \mathrm{U} / \mathrm{ml})$ or $\gamma$ IFN $(200 \mathrm{U} / \mathrm{ml}) ; 5 \%$ CM prepared from HUVE cells cultured in growth medium alone (-), or supplemented with IL-1, TNF, IL-2, or $\gamma$ IFN at the same concentrations as above. Uninduced HUVE-conditioned medium shows detectable BPA and CSA, with marked induction by IL-1 or TNF. Bars, 1 SD of duplicate cultures. 


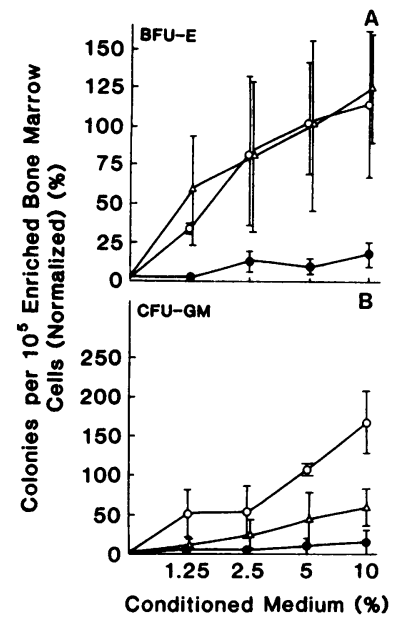

to IL-1 - than to TNF-treated HUVE. duced medium + stimulated the formation of very few relationship was observed with these controls and the colony numbers were never above background (data not shown).

$\mathrm{CM}$, the highest concentration possible in our culture system. CFU GM showed a greater response to IL-1-treated HUVE than TNF-treated HUVE (Fig. 3 B).

Endothelial cells produce GM CSF. To identify the hematopoietic growth factor being produced by immortalized and early passage human endothelial cells, we assayed for the presence of an mRNA species homologous to human $\mathrm{T}$ lymphoblast cell line-derived GM CSF. Serial dilutions of RNA extracted from HEC KSV cells, early passage human dermal fibroblasts, and IL-1-induced or uninduced HUVE cells were dotted onto nitrocellulose filters and hybridized to GM CSF cDNA probe. Fig. 4 shows an autoradiograph of such a dot-blot hybridization. Fibroblasts and uninduced endothelial cells contained little, if any, GM CSF mRNA, whereas both IL-1-induced endothelial cells and the immortalized HEC KSV line contained increased amounts of GM CSF mRNA (at least eightfold more than uninduced HUVE).

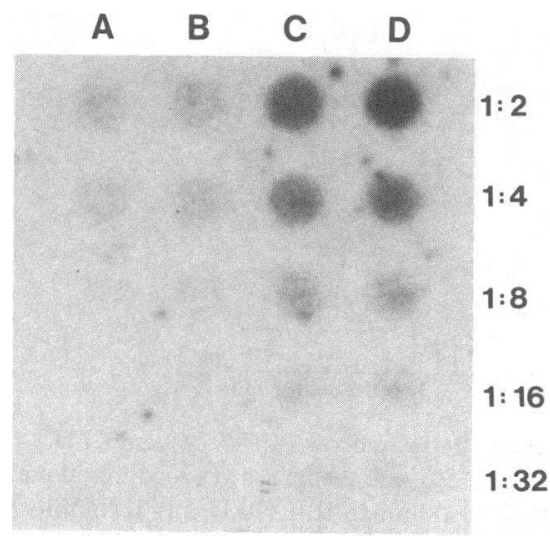

Figure 4. Autoradiogram of cytoplasmic RNA dot-blot hybridized to a probe for GM CSF. Serial twofold dilutions of RNA from human dermal fibroblasts $(A)$, HUVE $(B)$, HUVE after a 48-h exposure to recombinant human IL-1 at a concentration of $10 \mathrm{U} / \mathrm{ml}(C)$, and cell line HEC KSV $(D)$ are shown.

\section{Discussion}

It is established that cultured endothelial cells produce a hematopoietic growth factor (or factors) with both BPAs (6) and CSAs $(4,5)$. Furthermore, production of this factor(s) can be increased by incubating endothelial cells in monocyte-conditioned medium $(12,13)$. However, neither the nature of the factor nor the inducing monokine have been established. We demonstrate that both recombinant IL-1 and TNF can induce human endothelial cell production of GM CSF. GM CSF acts as a multilineage hematopoietin, inducing the proliferation of both myeloid and erythroid progenitors, and therefore our results are consistent with GM CSF being the only hematopoietin produced by endothelial cells. However, it will be necessary to directly probe endothelial cell RNA with cDNA probes to other hematopoietic growth factors as they become available to establish whether other hematopoietins are being produced in addition to GM CSF.

IL-1 and TNF are structurally dissimilar (26) and act on responsive target cells through distinct cell surface receptors (27). However, they both induce a similar spectrum of protein synthesis changes that is characteristic of the reaction to inflammation or tissue injury, the acute phase response (28). Our data broaden the range of proteins known to be induced by these two molecules. Whether GM CSF is an important acute phase protein in vivo is unknown, but it is interesting to speculate that production of GM CSF by endothelial cells at the site of inflammation through IL-1 release by monocyte/macrophages could contribute to neutrophilia (29), localization of neutrophils by migration inhibition (30), and subsequent neutrophil activation (31). IL-1-mediated GM CSA release may contribute to the leukocytosis of juvenile chronic myeloid leukemia (32).

The precise role of monocyte/macrophages in hematopoiesis is still uncertain. Monocytes (7-10) and T-lymphocytes $(33,34)$ have been previously reported as major circulating cell sources of BPA and CSA, whereas fixed "stromal" endothelial cells (4$6,12,13)$ and fibroblasts (3) are also capable of producing hematopoietic activities with a similar spectrum of activity. Monocytes may also release inhibitory factors $(11,35)$. Bagby and his colleagues reported that monocyte-derived recruiting activity can increase BPA and/or CSA production by $\mathrm{T}$ lymphocytes (15), endothelial cells (12), and fibroblasts (14). Recently, IL-1 $(36,37)$ and TNF (38) have been identified as monokines that can induce BPA/CSA release by fibroblasts (36) and endothelial $(37,38)$ cells. Although cellular RNA analysis has demonstrated that mitogen-stimulated blood mononuclear cells synthesize GM CSF messenger RNA, unequivocal identification of the GM CSF producer cells in this mixed lymphocytemonocyte population will depend on the use of in situ hybridization techniques. The use of molecular probes for IL-1 and GM CSF, together with the availability of pure populations of unactivated human monocytes (39), should now allow resolution of the controversial role of monocyte/macrophages in the production of GM CSF. Such studies are presently being carried out in our laboratories and should define whether the primary function of monocyte/macrophages is to directly produce GM CSF, indirectly stimulate GM CSF production by endothelial cells via monokines like IL-1 and TNF, or do both.

\section{Acknowledgments}

We thank Dr. David Nathan for helpful advice and support, Dr. Steven Clark for the labeled GM CSF probe, and Dr. Steven Mentzer for 
thoughtful suggestions. We thank Biogen for providing the recombinant IL-2 and Genentech for the recombinant human $\gamma$ IFN and TNF.

This work was supported by grants CA37169, HL32262, and CA39542 from the National Cancer Institute and by research grants from the Dyson Foundation and the American Cancer Society. Dr. Faller is a Fellow of the John A. Hartford Foundation.

\section{References}

1. Wolf, N. S. 1979. The haemopoietic microenvironment. Clin. Haematol. 8:469-500.

2. Weiss, L. 1981. Haemopoiesis in mammalian bone marrow. Ciba Found. Symp. 84:5-21.

3. Tsai, S., S. G. Emerson, C. A. Sieff, and D. G. Nathan. 1986. Isolation of a human stromal cell secreting hemopoietic growth factors. J. Cell. Physiol. 127:137-145.

4. Knutzon, S., and B. T. Mortensen. 1975. Growth stimulation of human bone marrow cells on agar culture by vascular cells. Blood. 46: 937-943.

5. Quesenberry, P. J., and M. A. Gimbrone. 1980. Vascular endothelium as a regulator of granulopoiesis: production of colony stimulating activity by cultured human endothelial cells. Blood. 56:1060-1067.

6. Ascensao, J. L., G. M. Vercellotti, H. S. Jacob, and E. D. Zanjani. 1984. Role of endothelial cells in human hematopoiesis: modulation of mixed colony growth in vitro. Blood. 63:553-558.

7. Chervenick, P. A., and A. F. LoBuglio. 1972. Human blood monocytes: stimulation of granulocyte and mononuclear colony formation in vitro. Science (Wash. DC). 178:164-166.

8. Golde, D. W., and M. J. Cline. 1972. Identification of colonystimulating cells in human peripheral blood. J. Clin. Invest. 51:29812983.

9. Zuckerman, K. S. 1981. Human erythroid burst-forming units. Growth in vitro is dependent on monocytes, but not $\mathrm{T}$ lymphocytes. $J$. Clin. Invest. 67:702-709.

10. Reid, C. P. L., L. C. Baptista, and I. Chanarin. 1981. Erythroid colony growth in vitro from human peripheral blood null cells: evidence for regulation by $\mathrm{T}$ lymphocytes and monocytes. Brit. J. Haematol. 48: 155-164.

11. Gordon, L. K., W. J. Miller, R. F. Branda, E. D. Zanjani, and H. S. Jacob. 1980. Regulation of erythroid colony formation by bone marrow (BM) macrophages. Blood. 55:1047-1050.

12. Bagby, G. C., E. McCall, K. A. Bergstrom, and D. Burger. 1983. A monokine regulates colony-stimulating activity production by vascular endothelial cells. Blood. 62:663-668.

13. Zuckerman, K. S., G. C. Bagby, Jr., E. McCall, B. Sparks, J. Wells, V. Patel, and D. Goodrum. 1985. A monokine stimulates production of human erythroid burst-promoting activity by endothelial cells in vitro. J. Clin. Invest. 75:722-725.

14. Bagby, G. C., E. McCall, and D. L. Layman. 1983. Regulation of colony stimulating activity production. Interactions of fibroblasts, mononuclear phagocytes and lactoferrin. J. Clin. Invest. 71:340-344.

15. Bagby, G. D., V. D. Rigas, R. M. Bennett, A. A. Vandenbark, and H. S. Garewal. 1981. Interaction of lactoferrin, monocytes, and $T$ lymphocyte subsets in the regulation of steady-state granulopoiesis in vitro. J. Clin. Invest. 68:56-63.

16. Sieff, C. A., S. G. Emerson, R. E. Donahue, D. G. Nathan E. A. Wang, G. G. Wong, and S. C. Clark. 1985. Human recombinant granulocyte macrophage colony stimulating factor: a multilineage hematopoietin. Science (Wash. DC). 230:1171-1173.

17. Sieff, C. A., S. G. Emerson, A. Mufson, T. G. Gesner, and D. G. Nathan. 1986. Dependence of highly enriched human bone marrow progenitors on hemopoietic growth factors and their response to recombinant erythropoietin. J. Clin. Invest. 77:74-81.

18. Todd, R. F., III, L. M. Nadler, and S. F. Schlossman. 1981. Antigens on human monocytes identified by monoclonal antibodies. $J$. Immunol. 126:1435-1442.

19. Griffin, J. D., J. Ritz, L. M. Nadler, and S. F. Schlossman. 1981. Expression of myeloid differentiation antigens on normal and malignant cells. J. Clin. Invest. 68:932-941.

20. Beverley, P. C. L., D. Linch, and D. Delia. 1980. Isolation of human haematopoietic progenitor cells using monoclonal antibodies. Nature (Lond.). 287:332-333.

21. Bigbee, W. L., M. Vanderlaan, S. S. N. Fong, and R. H. Jensen. 1983. Monoclonal antibodies specific for the $\mathrm{M}$ and $\mathrm{N}$ forms of human glycophorin A. Mol. Immunol. 20:1353-1362.

22. Wysocki, L. J., and V. L. Sato. 1978. "Panning" for lymphocytes: a method for cell selection. Proc. Natl. Acad. Sci. USA. 75:2844-2848.

23. Mentzer, S. J., S. J. Burakoff, and D. V. Faller. 1986. Adhesion of $T$ lymphocytes to human endothelial cells is mediated by LFA-1. $J$. Cell. Physiol. 126:285-291.

24. Flyer, D. C., S. J. Burakoff, and D. V. Faller. 1985. Retrovirusinduced changes in major histocompatibility complex antigen expression influence susceptibility to lysis by cytotoxic T lymphocytes. J. Immunol. 135:2287-2292.

25. Wong, G. G., J. S. Witek, P. A. Temple, K. M. Wilkens, A. C. Leary, D. P. Luxenberg, S. S. Jones, E. L. Brown, R. M. Kay, E. C. Orr, C. Shoemaker, D. W. Golde, R. J. Kaufman, R. M. Hewick, E. A. Wang, and S. C. Clark. 1985. Human GM-CSF: molecular cloning of the cDNA and purification of the natural and recombinant proteins. Science (Wash. DC). 228:810-815.

26. Aggarwal, B. B., W. J. Kohr, P. E. Hass, B. Moffat, S. A. Spencer, W. J. Henzel, T. S. Bringman, G. E. Nedura, D. V. Goeddel, and R. N. Harkins. 1985. Human tumor necrosis factor: production, purification, and characterization. J. Biol. Chem. 260:2345-2354.

27. Beutler, B., and A. Cerami. 1985. Recombinant interleukin-1 suppresses lipoprotein lipase activity in 3T3-L1 cells. J. Immunol. 135 3969-3971.

28. Perlmutter, D. H., C. A. Dinarello, P. I. Punsal, and H. R. Colton. 1986. Cachectin/tumor necrosis factor regulates hepatic acute phase gene expression. Clin. Res. 34:650. (Abstr.)

29. Donahue, R. E., E. A. Wang, D. K. Stone, R. Kaner, G. G. Wong, P. K. Sehgal, D. G. Nathan, and S. C. Clark. 1986. Stimulation of Laematopoiesis in primates by continuous infusion of recombinant human GM-CSF. Nature (Lond.). 321:872-875.

30. Gasson, J. C., R. H. Weisbart, S. E. Kaufman, S. C. Clark, R. M. Hewick, G. G. Wong, and D. W. Golde. 1984. Purified human granulocyte-macrophage colony-stimulating factor: direct action on neutrophils. Science (Wash. DC). 226:1339-1342.

31. Metcalf, D., C. G. Begley, G. R. Johnson, N. A. Nicola, M. A. Vadas, A. F. Lopez, D. J. Williamson, G. G. Wong, S. C. Clark, and E. A. Wang. 1986. Biologic properties in vitro of a recombinant human granulocyte-macrophage colony-stimulating factor. Blood. 67:37-45.

32. Bagby, G. C., R. Neerhout, D. Ridgeway, and E. McCall. 1986. The role of IL1 in the pathophysiology of juvenile chronic granulocytic leukaemia. Clin. Res. 34:655A. (Abstr.)

33. Nathan, D. G., L. Chess, D. G. Hillman, B. Clarke, J. Breard, E. Merler, and D. E. Housman. 1978. Human erythroid burst-forming unit: T-cell requirement for proliferation in vitro. J. Exp. Med. 147:324339.

34. Mangan, K. F., G. Chikkappa, L. Z. Sieler, W. B. Scharfman, and D. R. Parkingson. 1982. Regulation of human blood erythroid burstforming unit (BFU-E) proliferation by $T$ lymphocyte subpopulations defined by Fc receptors and monoclonal antibodies. Blood. 59:990-996.

35. Pelus, L. M., H. E. Broxmeyer, J. I. Kurland, and M. A. S. Moore. 1979. Regulation of macrophage and granulocyte proliferation: specificities of prostaglandin E and lactoferrin. J. Exp. Med. 150:277.

36. Zucali, J. R., C. A. Dinarello, D. J. Oblon, M. A. Gross, L. Anderson, and R. S. Weiner. 1986. Interleukin 1 stimulates fibroblasts to produce granulocyte-macrophage colony-stimulating activity and prostaglandin $\mathrm{E}_{2}$. J. Clin. Invest. 77:1857-1863.

37. Bagby, G. C., C. Dinarello, and E. McCall. 1986. Monocyte derived GM-CSF recruiting activity is IL-1. Clin. Res. 34:654A. (Abstr.)

38. Broudy, V. C., K. Kaushansky, G. M. Segal, J. M. Harlan, and J. W. Adamson. 1986. Tumour necrosis factor type $\alpha$ stimulates human endothelial cells to produce granulocyte/macrophage colony-stimulating factor. Proc. Natl. Acad. Sci. USA. 83:7467-7471.

39. Mentzer, S. J., S. J. Burakoff, P. M. Guyre, and D. V. Faller. 1986. Spontaneous aggregation as a mechanism for human monocyte purification. Cell. Immunol. 101:112-117. 